\title{
Fungal contamination and Fusarium mycotoxins in cereals grown in different tillage systems
}

\author{
V. Baliukoniené $\dot{1}^{1,3}$, B. Bakutis ${ }^{1}$, G. Januškevičienė \\ and R. Mišeikiené⿱ ${ }^{2}$ \\ ${ }^{1}$ Veterinary Academy of Lithuanian Health Sciences University, \\ Department of Food Safety and Animal Hygiene \\ ${ }^{2}$ Milking Training Centre \\ Tilžés 18, LT-47181, Kaunas, Lithuania
}

(Received 27 October 2010; revised version 6 September 2011; accepted 6 December 2011)

\begin{abstract}
The impact of two tillage systems (conventional and no-tillage) on cereal contamination with fungi and Fusarium mycotoxins was investigated. Samples of soil, cereal seeds, seedlings and freshly harvested grain were taken from plots of an agricultural cooperative in Lithuania. All samples were subjected to mycological analyses. Grain samples were also used for analysis of mycotoxins. In the soil under no-tillage, contamination with fungal spores was $92.9 \%$ higher compared to the soil under conventional tillage. In the soil of the no-tillage system we found 20 fungal genera, while in the soil under conventional tillage the number of genera was $15 \%$ lower. On cereal seedlings in the no-tillage system fungal spore content was $24.6 \%$ higher $(\mathrm{P}>0.05)$ and detection frequency of Fusarium fungi was $22.9 \%$ higher ( $\mathrm{P}>0.05$ ) than on seedlings in the conventional system. During harvest in feeding grain grown in the conventional tillage system, 2.2-8.0 $\log _{10} \mathrm{CFU} \mathrm{g} \mathrm{g}^{-1}$ fungal spores were detected, compared to 2.5-12.0 $\log _{10} \mathrm{CFU} \mathrm{g}^{-1}$ in grain in the no-tillage system. A significantly higher grain contamination with Fusarium spp. was detected in the no-tillage system. However, the deoxynivalenol, zearalenone and T-2 toxin content of grain was not considerably influenced by the different tillage systems, although it varied between species.
\end{abstract}

KEYWORDS: cereals, deoxynivalenol, fungi, grain, mycotoxins, tillage, zearalenone

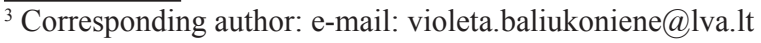




\section{INTRODUCTION}

In the last few years, particular interest was directed towards an increased risk of Fusarium infection and the production of the associated mycotoxins in small-grain cereals (Champeil et al., 2004; Vogelgsang et al., 2006) and maize (Maiorano et al., 2008). Different Fusarium spp. thrive in different climates. $F$. graminearum is most common in moist-warm regions, while $F$. culmorum and $F$. avenaceum prefer cooler zones (Doohan et al., 2003). In Lithuania, weather conditions are also favourable for Fusarium spp. In 2004, the detection frequency of Fusarium fungi was 38.5-50.0\%, and in 2005, 45.0-70.8\%. The most frequently isolated Fusarium spp. are F. culmorum, F. avenaceum, F. poae and F. sporotrichioides (Mačkinaitè et al., 2006). Infections can result in yield losses but more important is the contamination of grain by mycotoxins produced by the pathogens. Mycotoxins can enter the food chain in the field, during storage, or later.

The prevailing mycotoxins - deoxynivalenol, nivalenol, zearalenone, fumonisins and T2/HT2 toxins - are produced by various Fusarium spp. (Lugauskas et al., 2002). Levels of the mycotoxins produced by Fusarium cannot be reduced after harvest by means of classical transformation procedures (Eriksen and Alexander, 1998). These toxins are chemically and thermally stable. They may, therefore, be found both in raw material (grain) and in transformed products (flour, cakes, feed) or in products from animals fed with contaminated grain (meat, milk, eggs) (CAST, 2003). Mycotoxins may also cause poisoning incidents, the principal symptoms of which are nausea, lethargy, fatty and cancerous infiltrations and possibly even death (Eriksen and Alexander, 1998).

Different tillage systems are used to protect the soil from erosion and to maintain soil fertility and productivity (Hobbs, 2007). Conventional agriculture, based on intensive tillage with heavy machinery, is a real threat to soil fertility. Soil structure becomes increasingly unstable, the soil looses its infiltration capacity and is eventually degraded (Ekeberg and Riley, 1997). The no-tillage system (also known as no-till) is a plant production system without any tillage from previous harvest to direct seeding. This system offers the best conditions to conserve and improve soil structure. The litter layer protects the soil from rain (battering and erosion), and increases surface humidity (by limiting evaporation), soil temperature and inertia (Auskalnis and Feiza, 2006).

The main plant cultivation measures, however, influence also the intensity of Fusarium infection. Narrow cereal rotation systems, in combination with conservation tillage, are potentially more likely to promote Fusarium infection than wide cereal rotations including legumes or catch crops, and/or ploughing. It is therefore recommended to optimize tillage systems to control Fusarium infection in cereal production (Oldenburg et al., 2007). 
The aim of the present study was to estimate the effect of different tillage systems on quality cereal infection with fungi and contamination with Fusarium mycotoxins.

\section{MATERIAL AND METHODS}

\section{Tillage}

Field trials were established in plots of an agricultural cooperative, Lithuania in the Kaunas region. Soil type was identified as Endocalcari-Endohypogleyic Cambisol. Two tillage systems were applied for growing feeding cereals: 1. conventional tillage - deep ploughing $(23-25 \mathrm{~cm}) ; 2$. no-tillage - direct drilling. The other growing conditions of different cereals were similar.

\section{Samples}

Samples of soil, cereal seeds before sowing, seedlings and freshly harvested grain of spring and winter wheat (Triticum aestivum L.; cultivar - Širvinta 1), spring and winter barley (Hordeum vulgare f. distichon L.; spring barley cultivar - Auksiniai 3 and winter barley - Tilia), winter triticale $(\times$ Triticosecale Wittm.; cultivar - Tornado) and maize (Zea mays L.; cultivar - Kakon) were taken from single experimental plots ( 6 rotation crops in total, approximate size of each plot about 1.0 ha each).

The samples of soil, cereal seeds, seedlings and part of each grain sample were subjected to analysis of mycological contamination, and about $50 \mathrm{~g}$ of each grain sample were air-dried and kept at $-20^{\circ} \mathrm{C}$ until analysis of mycotoxin content.

\section{Analysis of sample contamination by fungi}

For determination of fungal colony-forming units per sample (CFU g-1), we used the dilution plating method (Lugauskas et al., 2004).

Internal grain contamination with Fusarium fungi was determined by plating the surface-sterilized grains (200 for each sample) on Petri dishes with potato dextrose agar, incubated for 7-8 days at $26 \pm 2^{\circ} \mathrm{C}$ (Mathur and Kongsdal, 2003). The infection level of grain was evaluated as detection frequency (\%). The purified single-spore cultures of Fusarium spp. were identified on the basis of their cultural and morphological characteristics according to Nelson et al. (1983), Samson and van Reenen-Hoekstra (1988) and Lugauskas et al. (2002). 


\section{Mycotoxin analysis}

The approximately $50 \mathrm{~g}$ grain samples were analysed by the ELISA (enzymelinked immunosorbent assay) method (Trucksess et al., 1995). Contamination with deoxynivalenol (DON), zearalenone (ZEN) and T-2 toxin was tested. The method is based on the antibody-antigen interaction. The Veratox test kits (Neogen Corporation, Scotland), approved by the AOAC (1999) (Certificate No. 950702) were used for the analysis. Mycotoxin extraction and tests were performed according to the manufacturer's instructions. The results were estimated taking into account the lowest calibration curve's mycotoxin concentration value (LODlimit of detection, in $\mu \mathrm{g} \mathrm{kg}^{-1}$ ), which is 100.0 for DON, 10.0 for ZEN and 7.5 for the $\mathrm{T}-2$ toxin.

\section{Statistical analysis}

Results of microbiological analysis of total fungal count (colony-forming units) in samples give into $\log _{10} \mathrm{CFU} \mathrm{g}^{-1}$ and processed using the SPSS for Windows 12.0 programme package (SPSS Inc. Il., USA, 2003). Analysis of variance (ANOVA) was applied for the statistical processing of data, and we calculated mean values and standard deviation. P-values of less than 0.05 were considered significant.

\section{RESULTS}

Monthly mean values of temperature and rainfall in the study area in the flowering-ripening period of cereals in 2007 are given in Table 1. In the spring of 2007, warm and dry weather prevailed, but excessive moisture was observed from May throughout the growing season. The weather of the first half of July was warm and dry, the second half being warm and damp. During the cereal flowering stage (mid and late June and early July), the conditions were conducive to the development and spread of fungi, especially Fusarium spp.

Table 1. Weather conditions in the study area in 2007

\begin{tabular}{lcccccc}
\hline Parameter & April & May & June & July & August & September \\
\hline Average temperature, ${ }^{\circ} \mathrm{C}$ & 6.9 & 13.5 & 17.6 & 17.2 & 18.7 & 14.4 \\
\pm deviation from long-term mean, ${ }^{\circ} \mathrm{C}$ & +0.4 & +1.3 & +2.0 & -0.4 & +2.1 & +2.4 \\
Average rainfall, mm & 15.8 & 98.2 & 61.5 & 118.1 & 50.8 & 26.6 \\
\% of long-term mean & 42.5 & 187.1 & 100.3 & 160.5 & 69.0 & 51.3 \\
Days with rainfall $\geq 1 \mathrm{~mm}$ & 4 & 12 & 9 & 16 & 11 & 2 \\
\hline
\end{tabular}

Soil is the main source of grain contamination by fungi. Under conventional tillage, the soil samples were contaminated with $7.0 \pm 0.5 \log _{10} \mathrm{CFU} \mathrm{g}^{-1}$ fungal 
spores on average. In the soil under conventional tillage, 17 genera of fungi were found. The most common genera were Alternaria (detection frequency 37\%), Fusarium (70\%), Mucor (10\%), Penicillium (10\%) and Trichoderma (62\%). The genus Fusarium was identified in $80 \%$ soil samples of conventional tillage. The dominant species were Fusarium poae, F. solani and F. oxysporium.

The soil under no-tillage was contaminated with $13.5 \pm 12.5 \log _{10} \mathrm{CFU} \mathrm{g}^{-1}$ fungal spores $(\mathrm{P}<0.05)$, i.e. $92.9 \%$ higher than under conventional tillage. In the soil of the no-tillage system, 20 genera of fungi were found. The species diversity of fungi was also higher. The most common genera were: Fusarium (84\%), Trichoderma (70\%), Pythium and Verticillium (50\%), Alternaria, Mortierella, Mucor, Rhizopus, Septoria (38\%) and Drechslera (25\%). The following fungi were most frequent in the soil of the no-tillage system: Alternaria alternaria, Drechslera sorokiniana, Epicoccum nigrum, Fusarium poae, F. oxysporium, F. solani, F. semitectum, Mortierella alpina, Rhizopus stolonifer var. stolonifer, Pythium sylvaticum, Septoria linicola, Sclerotinia sclerotiorum, Trichoderma viride and Verticillium alboatrum.

The analysis of fungal contamination of chemically treated cereal seeds before sowing revealed that spring and winter wheat were contaminated by $3.0 \pm 0.2$ and $2.5 \pm 0.1 \log _{10} \mathrm{CFU} \mathrm{g}^{-1}$, respectively; spring and winter barely seeds by $1.3 \pm 0.1$ and $2.0 \pm 0.3 \log _{10} \mathrm{CFU} \mathrm{g}{ }^{-1}$, respectively; winter triticale by $1.0 \pm 0.4 \log _{10} \mathrm{CFU} \mathrm{g}^{-1}$; and maize by $0.3 \pm 0.1 \log _{10}$ CFU g-1 . Species of Alternaria, Cladosporium, Fusarium and Penicillium were most frequent in seeds, and Alternaria alternaria dominated among them. Fungi of the genus Fusarium were detected in 2.0 and $5.0 \%$ of seeds of spring and winter wheat, respectively; 6.7 and $3.7 \%$ of spring and winter barely, respectively; $3.5 \%$ of winter triticale, and $0 \%$ of maize seeds.

Cereal seedling contamination by fungal spores is shown in Figure 1. When the conventional tillage system was used, seedling contamination with fungal

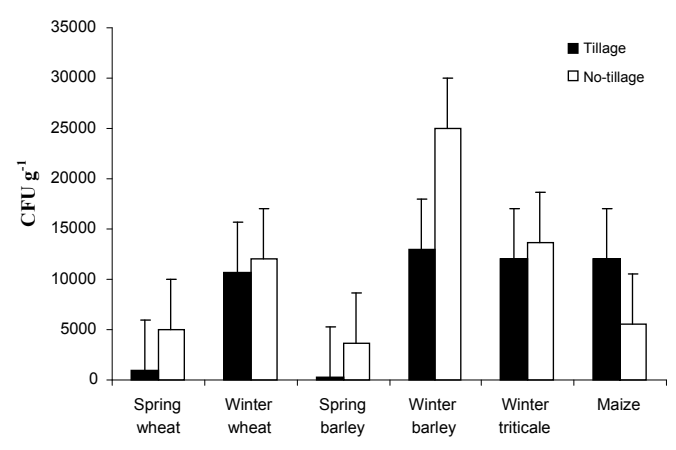

Figure 1. Contamination of various cereal seedlings by fungal spores $\left(\mathrm{CFU} \mathrm{g}{ }^{-1}\right)$. Error bar denotes standard deviation 
spores reached 0.3-1.0 $\log _{10} \mathrm{CFU} \mathrm{g} \mathrm{g}^{-1}$. When no-tillage system was used, 3.7$25.0 \log _{10}$ CFU g $g^{-1}$ fungal spores were detected. On cereal seedlings in the notillage system, fungal spore content was on average $24.6 \%$ higher $(\mathrm{P}>0.05)$ than on cereal seedlings in the conventional system. Among fungi isolated from winter and spring cereal seedlings, the most common genera were Alternaria (16.0-75.0\%), Cladosporium (1.3-46.6\%) and Fusarium (7.0-47.0\%). The highest fungal contamination was detected on winter barley seedlings, where in the notillage system, fungal contamination was $92.9 \%$ higher $(\mathrm{P}<0.05)$ than in the conventional system.

Our research has shown that in cereal seedlings under no-tillage the detection frequency of Fusarium spp. was $22.9 \%$ higher $(\mathrm{P}>0.05)$, compared to cereal seedlings in the conventional system (Figure 2). Winter triticale seedlings in the conventional system were most contaminated with Fusarium spp. (36.7\%), while spring wheat was the least contaminated (7.0\%). Where we used no-tillage, the contamination by Fusarium spp. ranged from $26.7 \%$ of maize seedlings to $47.7 \%$ of winter wheat seedlings.

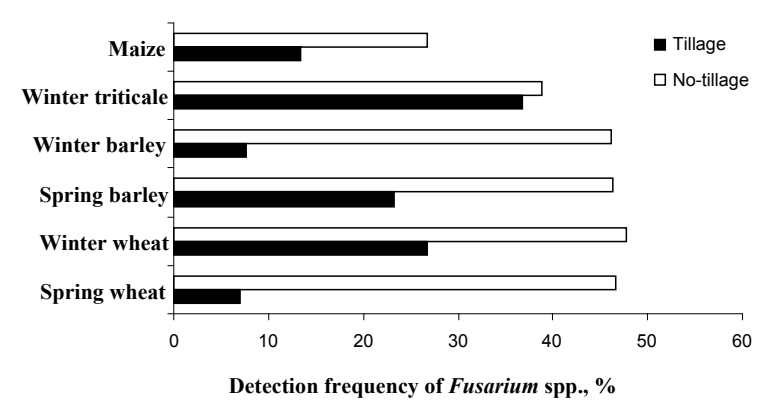

Figure 2. Detection frequency of Fusarium spp. on cereal seedlings

Fourteen species of Fusarium were identified in this study, but F. avenaceum, $F$. graminearum, $F$. poae and $F$. sporotrichioides dominated on cereal seedlings.

During harvest, 2.2-8.0 $\log _{10} \mathrm{CFU} \mathrm{g}^{-1}$ fungal spores were detected in grain in the conventional system, compared to $2.5-12.0 \log _{10} \mathrm{CFU} \mathrm{g}{ }^{-1}$ fungal spores in grain in the no-tillage system (Figure 3 ). The most severe fungal contamination was recorded for winter wheat in both systems, but under no-tillage it was contaminated $50 \%$ higher than under conventional tillage. Also generally, grain contamination with fungal spores was higher under conventional tillage but differences between the two tillage systems were not significant. An exception was maize, where an inverse trend was observed and the difference was significant. 


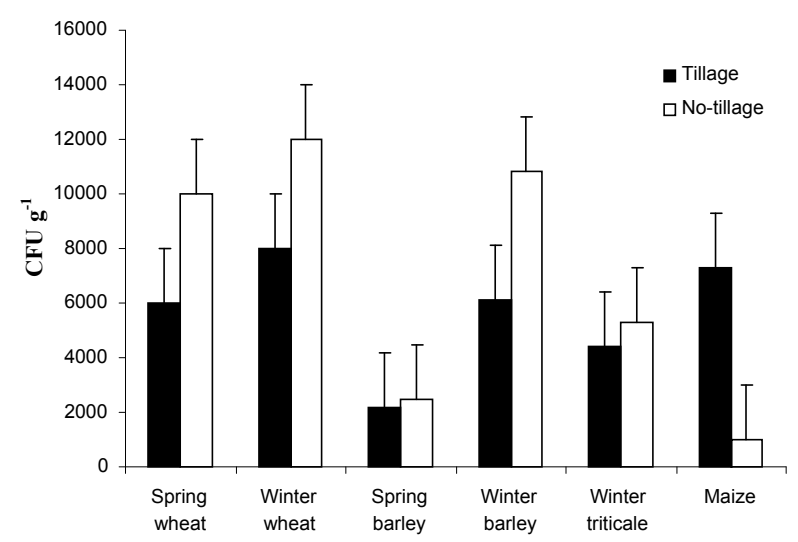

Figure 3. Grain surface contamination by fungal spores (CFU $\left.\mathrm{g}^{-1}\right)$ during harvesting. Error bar denotes standard deviation

The predominant fungi present in freshly harvested grain samples were species of the genera Alternaria (30.0-50.0\%), Cladosporium (26.7-47.0\%), Fusarium (36.0-77.0\%) and Biporalis (7.0\%) (in barley grain).

The average detection frequency of Fusarium in grain samples (Figure 4) was significantly higher in the no-tillage system. The highest Fusarium frequency was observed in spring barley and maize from the no-tillage system.

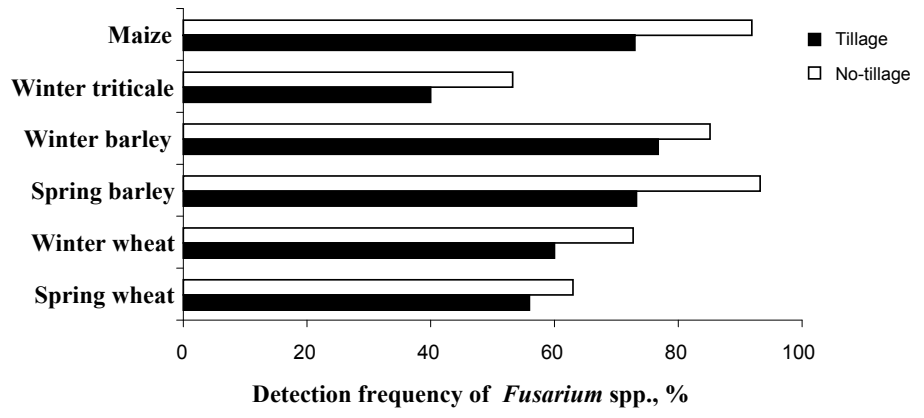

Figure 4. Detection frequency of Fusarium spp. in freshly harvested grain

Fusarium mycotoxin content of grain samples (Table 2) is presented separately for deoxynivalenol, zearalenone and T-2 toxin. Their content varied but it was not considerably influenced by the different tillage systems applied in the present study. 
Table 2. Mycotoxin content of freshly harvested grain, $\mu \mathrm{g} \mathrm{kg}^{-1}$

\begin{tabular}{|c|c|c|c|c|c|c|}
\hline \multirow{3}{*}{ Grain } & \multicolumn{6}{|c|}{ Tillage system } \\
\hline & \multicolumn{3}{|c|}{ conventional tillage } & \multicolumn{3}{|c|}{ no-tillage } \\
\hline & $\mathrm{DON}^{1}$ & $\mathrm{ZEN}^{2}$ & T-2 toxin & $\mathrm{DON}^{1}$ & $\mathrm{ZEN}^{2}$ & $\mathrm{~T}-2$ toxin \\
\hline Spring wheat & $\operatorname{tr}$ & 21.0 & 10.0 & $\operatorname{tr}$ & 21.0 & 15.0 \\
\hline Winter wheat & $\operatorname{tr}$ & $\operatorname{Tr}$ & 13.0 & $\operatorname{tr}$ & 20.0 & $\operatorname{tr}$ \\
\hline Spring barley & 180.0 & 20.0 & $\operatorname{tr}$ & 110.0 & 30.0 & 10.0 \\
\hline Winter barley & 100.0 & 10.0 & $\operatorname{tr}$ & 100.0 & 25.0 & 8.0 \\
\hline Winter triticale & 50.0 & 10.0 & $\operatorname{tr}$ & 170.0 & 30.0 & $\operatorname{tr}$ \\
\hline Maize & 100.0 & 103.0 & $\operatorname{tr}$ & 120.0 & 20.0 & $\operatorname{tr}$ \\
\hline
\end{tabular}

${ }^{1}$ DON - deoxynivalenol; ${ }^{2} \mathrm{ZEN}$ - zearalenone; tr - traces

\section{DISCUSSION}

Our experimental evidence indicates that the no-tillage system increases the frequency of fungal spores, whereas deep tillage decreases it. Similarly, limited tillage systems increase the number of Fusarium spores in the soil (Parry et al., 1995; Oldenburg et al., 2007).

Fungi can also affect seed quality and several pathogens may infect seedlings from contaminated seeds. This applies to Fusarium, Drechslera, Alternaria, Cladosporium, Penicillium and other fungal genera (Forsberg et al., 2005). The seed-borne fungi may not only lower seed germination but also reduce seed vigour, resulting in a low yield. Some pathogenic fungi destroy the young seedlings before they appear on the surface of the soil. Other fungi can cause a range of plant diseases (Steinkellner et al., 2002). Chemically treated cereal seeds were also contaminated by fungal spores: from $0.3 \log _{10} \mathrm{CFU} \mathrm{g}{ }^{-1}$ on maize to $3.0 \log _{10}$ $\mathrm{CFU} \mathrm{g^{-1 }}$ on winter wheat.

The climate plays a role at all stages of development of the fungus. In spring, the climate determines the type and quality of spores produced, together with the date of their dispersal and thus the intensity of the disease. Indeed, the coincidence of the dates of spore dispersal and crop flowering, marks the start of the critical phase of infection for plants. In summer, together with the virulence characteristics of the fungal strain and the intrinsic resistance of the plant, climate controls the competition between pathogen species, thereby controlling the rate of mycelium growth in the plant (Champeil et al., 2004). The climate may also affect the production of fungal toxins in the field (CAST, 2003).

The most prevalent fungi in cereal grain in the temperate zone are Fusarium spp. In the last ten years, the increased level of colonization and infection by Fusarium, particularly of ripening ears of cereals, has attracted much attention: firstly, because of the significant effects on the yield and quality of freshly harvested grain, and secondly, because of the ability of Fusarium spp. to produce 
a wide range of mycotoxins, which can enter the human and animal food chains (Maiorano et al., 2008). In Lithuania, weather conditions are also favourable for the occurrence of Fusarium spp., where the frequency of detection of these fungi is sometimes as high as $93.5 \%$ (Mačkinaitė et al., 2006).

Our research has shown that $26.7-47.7 \%$ of cereal seedlings were contaminated by Fusarium spp. in the no-tillage system, compared to $7.0-36.7 \%$ of seedlings in the conventional system.

As a result of fungal growth, cereal grain is often contaminated by mycotoxins. Food safety issues, due to mycotoxins of Fusarium, can be very important for the food chain.

Deoxynivalenol (DON) and zearalenone (ZEN) were prevalent mycotoxins in the analysed grain samples. The highest DON concentration was observed in barley and maize, but differences between soil cultivation methods were generally low. The only exception was triticale, where DON and ZEN content was at least 3 -fold higher in the no-tillage system. This corresponds with Schaafsma et al. (2005), who reported that environmental effects accounted for $48 \%$ of variation in DON content in wheat grain, followed by variety $(27 \%)$. Those authors also found that the effect of soil cultivation was very small in most experimental years. Koch et al. (2006) concluded from their on-farm large-scale experiments that annual weather conditions affect Fusarium infection and DON concentration to the same extent as cultivar susceptibility, and in comparison with these factors, the applied tillage system is less important. Dill-Macky and Jones (2000) found only small differences in DON content between mouldboard plough, chisel plough and notill plots.

By contrast, Champeil et al. (2004) suggested that the level of grain contamination with mycotoxins depends on both climate and cropping system. Mycotoxin levels were highest in the year 2000, when disease severity was the highest. Contamination levels were highest in the direct drilling (i.e. no-tillage) system.

\section{CONCLUSIONS}

Our data indicate a significant effect of tillage system on the detection frequency of Fusarium spp. in grain, but no significant effect on grain contamination with deoxynivalenol, zearalenone and T-2 toxin. The no-tillage system promotes the development of fungi in grain and thus may lower the quality of grain, but fungal species diversity is higher in this system. 


\section{REFERENCES}

AOAC, 1999. Association of Official Analytical Chemists, Official Methods of Analysis. 16 ${ }^{\text {th }}$ Edition. Washington, DC

Auskalnis A., Feiza V., 2006. The impact of soil tillage minimization on sandy loam soil. Agriculture 93, 55-64

CAST, 2003. Mycotoxins: Risks in Plant, Animal, and Human Systems. Council for Agricultural Science and Technology. Ames, Iowa, pp. 36-48

Champeil A., Dore T., Fourbet J.F., 2004. Fusarium head blight: epidemiological origin of the effects of cultural practices on head bligth attacks and the production of mycotoxins by Fusarium in wheat grains. Plant Sci. 166, 1389-1415

Dill-Macky R., Jones R.K., 2000. The effect of previous crop residues and tillage on Fusarium head blight of wheat. Plant Dis. 84, 71-76

Doohan F.M., Brennan J., Cooke B.M., 2003. Influence of climatic factors on Fusarium species pathogenic to cereals. Eur. J. Plant Pathol. 109, 755-768

Ekeberg E., Riley H., 1997. Tillage intensity effects on soil properties and crop yields in a long-term trial on morainic loam soil in southeast Norway. Soil Tillage Res. 42, 277-293

Eriksen G.S., Alexander J. (Editors), 1998. Fusarium Toxins in Cereals - a Risk Assessment. TemaNord Report 502. Nordic Council of Ministers, Copenhagen (Denmark)

Forsberg G., Johnsson L., Lagerholm J., 2005. Effect of aerated steam seed treatment on seed-borne diseases and crop yield. J. Plant Dis. Protect. 112, 247-256

Hobbs P.R., 2007. Conservation agriculture: wath is it and why is it important for future sustainable food production? J. Agr. Sci. 145, 127-137

Koch H.J., Pringas C., Maerlaender B., 2006. Evaluation of environmental and management effects on Fusarium head blight infection and deoxynivalenol concentration in the grain of winter wheat. Eur. J. Agron. 24, 357-366

Lugauskas A., Krasauskas A., Repečkienė J., 2004. Ecological factors predetermining the distribution of fungi on cereal grains and soybean seeds. Ekologija 2, 21-32

Lugauskas A., Paškevičius A., Repečkienè J. 2002. Pathogenic and toxic microorganisms in the human environment (in Lithuanian). Aldorija. Vilnius

Mačkinaitė R., Kačergius A., Lugauskas A., Repečkienė J., 2006. Contamination of cereal grain by Fusarium micromycetes and their mycotoxins under Lithuanian climatic conditions. Ekologija $3,71-80$

Maiorano A., Blandino M., Reyneri A., Vasara F., 2008. Effects of maize residues on the Fusarium spp. infection and deoxynivalenol (DON) contamination of wheat grain. Crop Prot. 27, 182188

Mathur S.B., Kongsdal O., 2003. Common Laboratory Seed Health Testing Methods for Detecting Fungi. Denmark (Copenhagen), pp. 200-255

Nelson P.E., Tousson T.A., Marasas W.F.O., 1983. Fusarium Species. An Illustrated Manual for Identifi Cation. The Pennsylvania State University Press, pp. 20-320

Oldenburg E., Brunotte J., Weinert J., 2007. Strategies to reduce DON contamination of wheat with different soil tillage and variety systems. Mycotoxin Res. 23, 73-77

Parry D.W., Jenkinson P., McLeod L., 1995. Fusarium ear blight (scab) in small grain cereals - a review. Plant Pathol. 44, 207-238

Samson R.A., van Reenen-Hoekstra E.S., 1988. Introduction to Foodborne Fungi. $3^{\text {rd }}$ Edition. Centraalbureau voor Schimmelcultures (CBS), Institute of the Royal Netherlands Academy of Arts and Sciences. Baarn, Delft

Schaafsma A.W., Hooker D.C., Miller J.D., 2005. Progress and limitations with respect pre-harvest forecasting of Fusarium toxins in grains. Phytopathology 95, 123-130 
Steinkellner S., Mayrhofer V.S., Langer I., 2002. Influence of tillage on Fusarium spp. in different crop rotation systems. Mycotoxin Res. 18, 11-15

Trucksess M.W., Thomas F., Young K., Stack M.E., Fulgueras W.J., Page S.W., 1995. Survey of deoxynivalenol in U.S. 1993 wheat and barley crops by enzyme-linked immunosorbent assay. J. AOAC. Int. 78, 631-636

Vogelgsang S., Hecker A., Forrer H.R., 2006. Fusarium head blight and mycotoxins in cereals potential strategies to control contamination under conservation tillage. In: J. Grajewski, M. Twarużek, A. Szymańska (Editors). Proceedings of $28^{\text {th }}$ Mycotoxin Workshop. Bydgoszcz (Poland), p. 31 